\title{
Perceptions of opportunities for physical activity in 28 European countries
}

Filippos T. Filippidis $\mathrm{PhD}$, Anthony A. Laverty $\mathrm{PhD}$

Department of Primary Care and Public Health, School of Public Health, Imperial College London, United Kingdom

\section{Corresponding author:}

Filippos T Filippidis

Department of Primary Care and Public Health, School of Public Health, Imperial College London, St Dunstan's Road, London W6 8RP

E-mail: f.filippidis@imperial.ac.uk Telephone: +44 (0)20 75947142

Abstract word count: 249

Word count: 2198

Number of tables: 2

Number of figures: 0

\section{Conflict of interest:}

The authors declare that there is no conflict of interest.

\section{Financial disclosure:}

No financial disclosures were reported by the authors of this paper. 


\section{Abstract}

Introduction: This study examined the relationship between perceptions of opportunities for physical activity in the local area and physical activity levels in European adults. Methods: Data for 20,673 adults aged 18-64 were taken from the representative Eurobarometer survey (wave 80.2, 2013) of 28 European Union (EU) countries. Achieving recommended levels of physical activity and Metabolic Equivalent of Task-minutes (METmins) per week were constructed from self-reports of frequency and duration of walking, moderate and vigorous physical activity. Relationships between these outcomes and perceptions of opportunities for physical activity in the local area were assessed using logistic and linear regression as appropriate; trends in these perceptions were measured between 2002 and 2013.

Results: Respondents stating that their local area offers opportunities for physical activity were more likely to meet recommended levels of physical activity (Adjusted Odds Ratio $[\mathrm{aOR}]=1.56)$. Across all EU countries the percentage of people reporting that their local area offers these opportunities increased slightly between 2005 (71.4\%) and 2013 (79.3\%, $\mathrm{p}<0.001)$. Reporting that the local area offers opportunities for physical activity was associated with more moderate (17 minutes/week) and vigorous (15 minutes/week) physical activity and with 23 more minutes of walking per week.

Conclusion: Perceptions of opportunities for physical activity in the local area were associated with increased levels of all types of physical activity. Despite small improvements in perceptions of opportunities in the local area over the past decade, a variety of further interventions will be required to reduce the disease burden resulting from low physical activity levels.

Keywords: Motor activity; Europe; Cross-sectional studies; Exercise; Walking 


\section{Introduction}

Physical activity is one of the major determinants of population health, which has led the World Health Organization (WHO) to develop detailed guidelines and prioritise the promotion of physical activity (World Health Organization, 2010). There is a growing body of evidence that highlights the importance of structural and environmental factors, including, among others, aesthetics (Van Dyck et al., 2012), walkability (Thielman et al., 2015), access to facilities and environmental quality (Van Holle et al., 2012). Promoting increased physical activity through modifications of the urban environment has been identified as one of the supporting interventions that have been included in WHO's “Action Plan for implementation of the European Strategy for the Prevention and Control of Noncommunicable Diseases 2012-2016" (World Health Organization, 2012).

Recent work has highlighted that substantial numbers of the European population do not achieve recommended levels of physical activity, and that this varies widely both between and within countries (Gerovasili et al., 2015). Findings such as these describing the extent of low levels of physical activity in Europe have generated interest in potential explanations and the extent to which these patterns can be modified. Local environments have an important part to play in this, and have been a focus of research for some time (Sallis et al., 2009). Early reviews concluded that perceptions of the local environment were strongly linked to physical activity levels (Duncan et al., 2005), but more recent reviews in the European context have cast some doubt on the importance of this, both overall and for specific aspects such as access to recreational facilities (Van Holle et al., 2012). However, while there have been a number of country-specific studies, the associations between perceptions of the local environment and physical activity across the whole of the EU have not been examined to date. Additionally, the extent to which these perceptions have changed over time and hence whether this could be a potential explanation for declining levels of activity is littleinvestigated.

We analysed data from a 2013 Eurobarometer survey to assess the associations between perceptions of opportunities for physical activity in the local area and levels of physical activity in the European Union, as well as the trends in these over the previous decade. 


\section{Methods}

Study sample

We analysed data from the Eurobarometer survey, wave 80.2. Data from $n=27,919$ respondents from 28 EU countries were collected in November-December 2013. Among them, $n=20,697$ were between 18 and 64 years old; this subsample was analysed in the present study, as WHO recommendations for physical activity are different for older and younger people (World Health Organization, 2010). A multi-stage sampling design was employed to obtain a representative sample of residents aged $\geq 15$ years in each of the 28 countries. Respondents were selected from households with probability proportional to population size and density. Interviews were conducted in people's homes and in the language of each country.. Details on the methodology and questionnaire used in the survey, as well as the dataset are publicly available (European Commission, 2014), hence no ethical approval was required.

For the serial cross-sectional analyses, data from four waves of the Eurobarometer surveys were analysed. Eurobarometer surveys typically cover countries that are members of the European Union and follow the same sampling methodology, but each sample is selected independently, so participants are different in each wave. Therefore, data for 15 countries (EU15) were available in all four waves, while data for the thirteen newest members of the EU were only available in three waves (with the exception of Croatia, which was not included in the 2009 wave). The effective sample sizes were the following: wave 58.2 (2002; $\mathrm{n}=12,961 ; 15$ countries), wave 64.3 (2005; $\mathrm{n}=20,939 ; 28$ countries), wave 72.3 (2009; $\mathrm{n}=19,803 ; 27$ countries $)$ and wave $80.2(2013 ; \mathrm{n}=20,697 ; 28$ countries $)$.

Measures

\section{Sociodemographic data}

Data were collected on respondents' gender (male; female), age (18-24; 25-39; 40-54; or $\geq 55$ years); area of residence (rural area or village; town); age at completion of full-time education ( $\leq 15 ; 16-19$; or $\geq 20$ years); and frequency at which respondents reported experiencing difficulty paying monthly bills, as a proxy for income ("most of the time"; "from time to time"; "almost never/never"). Member countries were grouped into four sub- 
regions, based on the United Nations geoscheme (United Nations Statistics Division): Southern Europe (Croatia, Greece, Italy, Malta, Portugal, Slovenia, Spain, and Republic of Cyprus), Western Europe (France, Belgium, Austria, Germany, The Netherlands, Luxembourg), Northern Europe (Denmark, Ireland, United Kingdom, Latvia, Lithuania, Estonia, Finland, Sweden), and Eastern Europe (Slovakia, Czech Republic, Hungary, Poland, Bulgaria, Romania).

\section{Physical activity}

Frequency and average duration of walking, moderate and vigorous physical activity were assessed using questions from the International Physical Activity Questionnaire (IPAQ), which has been validated in several European countries (Lee et al., 2011). The total time spent in each of these was calculated for each individual, by multiplying the number of days during which they engaged in each type of activity with the amount of time they usually spend when doing such activities. Individuals who reported at least 150 minutes of moderate physical activity -including walking- or at least 75 minutes of vigorous activity per week, or an equivalent combination of moderate and vigorous activity and therefore met the WHO guidelines for physical activity, were classified as doing recommended levels of physical activity. To estimate total physical activity per week Metabolic Equivalents of Task (METs) were also used and the total amount of MET-minutes (MET-mins) per week was calculated for each respondent, according to reported time spent walking and doing moderate or/and vigorous physical activity. Further details on the methodology have been described elsewhere (Gerovasili et al., 2015).

\section{Opportunities for physical activity}

Respondents were asked to say if they agree ("totally agree" and "tend to agree") or disagree ("totally disagree" and "tend to disagree") with the statement "The area where I live offers me many opportunities to be physically active".

\section{Statistical analysis}

Percentages with 95\% Confidence Interval (95\% CI) are presented. We fitted a multivariable logistic regression model to assess the association between perceptions of opportunities to be physically active in the area where the respondents live and meeting the WHO guidelines for physical activity, adjusting for age; gender; education; geographic region; area of residence; and difficulty in paying bills. A similar linear regression model, with total MET-mins per 
week as the dependent variable was also fitted. We also fitted linear regression models with the number of minutes per week that respondents spent walking; doing moderate; and vigorous physical activity, adjusted for the aforementioned factors. Finally, logistic regression models with a time variable, adjusting for age, gender and area of residence, were used in order to assess time trends in the proportion of adults who responded that the area where they live offers many opportunities to be physically active. Logistic regression results are presented as Adjusted Odds Ratios (AOR) with 95\% CI. Data were weighted to ensure nationally representative estimates. 


\section{Results}

The distribution of the sample18-64 years in the 2013 wave are shown in Supplementary Table 1 and proportions of people meeting the WHO guidelines in Supplementary Table 2. Those who agreed that the area where they live offers many opportunities for physical activity were more likely to meet the WHO guidelines for physical activity (AOR=1.56; 95\% CI: 1.38 to 1.76 ) compared to those who tended to disagree or disagreed with this statement, after adjusting for gender; age; area of residence; difficulty to pay bills; region; and education. Similarly, those who agreed with the statement reported 267.1 (95\% CI: 128.1 to 406.1) more MET-mins of physical activity per week, compared to those who disagreed (Table 1).

Perceptions of the local area having opportunities for physical activity was associated with 23.2 more minutes of walking per week ( $95 \%$ CI: 10.5 to 35.9 ), 17.4 more minutes of moderate activity (95\% CI: 6.5 to 28.3 ) and 14.7 more minutes of vigorous activity (95\% CI: 4.1 to 25.3 ) per week (data not shown).

The serial cross-sectional analyses showed that the proportion of respondents who agreed -or tended to agree- that the area where they live offers many opportunities for physical activity increased from $75.3 \%$ in 2002 to $82.8 \%$ in 2013 in the 15 older members of the EU (p for trend $<0.001$ ) and from $71.4 \%$ in 2005 to $79.0 \%$ in 2013 in the 28 EU countries (Table 2). There was a positive linear trend $(\mathrm{p}<0.05)$ in sixteen of the countries, while ten countries showed no statistically significant trend over the time period. Greece $(71.1 \%-62.2 \%)$ and Romania $(56.9 \%-47.1 \%)$ were the only countries in which there was a statistically significant $(\mathrm{p}<0.05)$ negative linear trend. 


\section{Discussion}

Our analysis found that perceptions that the local area provides opportunities for physical activity were associated with higher levels of all types of physical activity in the EU, and that perceptions of available opportunities for physical activity have improved over time in the majority of the EU countries.

The proportion of adults 18-64 years old who believed that the area where they live offers many opportunities for physical activity increased in the majority of the EU member countries between the year of the first available survey (2002 or 2005) and 2013. Moreover, in most of the countries where there were no statistically significant positive trends, the levels of agreement with the above statement were already high. This may reflect the fact that many European countries have developed guidelines and policies with an environmental dimension in order to improve levels of physical activity among their populations (Daugbjerg et al., 2009). However, there were two notable exceptions, Greece and Romania, where perceptions regarding the opportunities for physical activity worsened during the study period. The decline was gradual in Romania, whereas in Greece it took place mostly after 2009, in a period when the country was facing a deep recession and levels of physical activity actually improved (Filippidis et al., 2014). This is consistent with other evidence on the association of economic recessions with physical activity (Franco et al., 2007) and highlights the complex interaction between factors that can influence physical activity.

Despite the fact that a high proportion of the EU population states that there are opportunities for physical activity in their local area, the number of European adults who fail to meet recommended levels of activity is high (Gerovasili et al., 2015). Previous work has highlighted these low levels of activity and suggested that the Eurobarometer survey be used to target health promotion efforts (Sjöström et al., 2006). Other non-health sector policies, such as creating bike lanes (Pucher et al., 2010), new walking trails (Muller-Riemenschneider et al., 2009) or improving access to recreational facilities (Van Holle et al., 2012) can also be used to increase population levels of physical activity. Therefore such policies should be considered, especially by countries in which there was no improvement in perceptions over time, taking also into account that environmental interventions to encourage physical activity are very cost-effective (Muller-Riemenschneider et al., 2009) and may have beneficial 
secondary effects as well, such as reducing greenhouse-gas emissions (Woodcock et al., 2009)

Strengths and limitations

We analysed multiple waves of the Eurobarometer surveys, which follow the same sampling methodology and use the same questions across years and countries. Therefore, we were able to make reliable comparisons between countries and across several years within the EU. Nonetheless, as Eurobarometer does not sample the same people across different waves we were unable to perform longitudinal analyses. Additionally, data on physical activity were self-reported and so levels may have been overestimated across the sample (Lee et al., 2011), although any measurement error resulting from this is unlikely to have introduced bias to comparisons between and within countries. Further international research should focus on using objective physical activity assessment for greater accuracy in determining levels of activity, such as has been recently undertaken by the International Physical Activity and the Environment (IPEN) studies (Brownson et al., 2009). Also, differences in the questions that assessed physical activity between waves did not allow us to examine time trends in physical activity.

Moreover, the question on opportunities offered in the local area assessed respondents' perceptions, rather than objective measures. While these may not be an accurate reflection and could be affected by personal traits and misconceptions, the role of perception on behaviour has been noted and there remains debate between the relative importance of subjective and objective measures (Brownson et al., 2009; Tilt et al., 2007). We were also unable to ascertain for how long respondents had lived at their current address, nor explore neighbourhood self-selection which may have an impact on these relationships. This study was additionally unable to separate physical activity into domains such as transport, work or leisure, although we did assess different types of activity (walking; moderate; vigorous). Some previous studies have focused on only one of these and research using such a breakdown has emphasised that associations with the environment may differ across these domains (Arango et al., 2013).

\section{Conclusions}


While there have been increases in perceptions of opportunities for physical activity in the local area in Europe, such provision is still linked to achieving recommended levels of physical activity. Perceived opportunities to be active in the local area was associated with all types of physical activity, which strengthens calls for wide reaching policies to promote physical activity. 


\section{References}

Arango, C.M., Paez, D.C., Reis, R.S., Brownson, R.C., Parra, D.C., 2013. Association between the perceived environment and physical activity among adults in Latin America: a systematic review. The international journal of behavioral nutrition and physical activity $10: 122$.

Brownson, R.C., Hoehner, C.M., Day, K., Forsyth, A., Sallis, J.F., 2009. Measuring the built environment for physical activity: state of the science. American journal of preventive medicine 36:S99-123 e12.

Daugbjerg, S.B., Kahlmeier, S., Racioppi, F., Martin-Diener, E., Martin, B., Oja, P., Bull, F., 2009. Promotion of physical activity in the European region: content analysis of 27 national policy documents. Journal of physical activity \& health 6:805-17.

Duncan, M.J., Spence, J.C., Mummery, W.K., 2005. Perceived environment and physical activity: a meta-analysis of selected environmental characteristics. The international journal of behavioral nutrition and physical activity 2:11.

European Commission, 2014. Eurobarometer 80.2, October 2013. GESIS Data Archive: ZA5877, Data file version 1.0.0, doi:10.4232/1.12010. TNS OPINION, Brussels.

Filippidis, F.T., Schoretsaniti, S., Dimitrakaki, C., Vardavas, C.I., Behrakis, P., Connolly, G.N., Tountas, Y., 2014. Trends in cardiovascular risk factors in Greece before and during the financial crisis: the impact of social disparities. European journal of public health 24:9749.

Franco, M., Ordunez, P., Caballero, B., Tapia Granados, J.A., Lazo, M., Bernal, J.L., Guallar, E., Cooper, R.S., 2007. Impact of energy intake, physical activity, and population-wide weight loss on cardiovascular disease and diabetes mortality in Cuba, 1980-2005. American journal of epidemiology 166:1374-80.

Gerovasili, V., Agaku, I.T., Vardavas, C.I., Filippidis, F.T., 2015. Levels of physical activity among adults 18-64 years old in 28 European countries. Preventive medicine 81:87-91. Lee, P.H., Macfarlane, D.J., Lam, T.H., Stewart, S.M., 2011. Validity of the International Physical Activity Questionnaire Short Form (IPAQ-SF): a systematic review. The international journal of behavioral nutrition and physical activity 8:115. Muller-Riemenschneider, F., Reinhold, T., Willich, S.N., 2009. Cost-effectiveness of interventions promoting physical activity. British journal of sports medicine 43:70-6. Pucher, J., Dill, J., Handy, S., 2010. Infrastructure, programs, and policies to increase bicycling: an international review. Preventive medicine 50 Suppl 1:S106-25. 
Sallis, J.F., Bowles, H.R., Bauman, A., Ainsworth, B.E., Bull, F.C., Craig, C.L., Sjostrom, M., De Bourdeaudhuij, I., Lefevre, J., et al., 2009. Neighborhood environments and physical activity among adults in 11 countries. American journal of preventive medicine 36:484-90. Sjöström, M., Oja, P., Hagströmer, M., Smith, B., Bauman, A., 2006. Health-enhancing physical activity across European Union countries: the Eurobarometer study. Journal of Public Health 14:291-300.

Thielman, J., Rosella, L., Copes, R., Lebenbaum, M., Manson, H., 2015. Neighborhood walkability: Differential associations with self-reported transport walking and leisure-time physical activity in Canadian towns and cities of all sizes. Preventive medicine 77:174-80. Tilt, J.H., Unfried, T.M., Roca, B., 2007. Using objective and subjective measures of neighborhood greenness and accessible destinations for understanding walking trips and BMI in Seattle, Washington. American journal of health promotion : AJHP 21:371-9.

United Nations Statistics Division, Composition of macro geographical (continental) regions, geographical sub-regions, and selected economic and other groupings.

Van Dyck, D., Cerin, E., Conway, T.L., De Bourdeaudhuij, I., Owen, N., Kerr, J., Cardon, G., Frank, L.D., Saelens, B.E., et al., 2012. Perceived neighborhood environmental attributes associated with adults' transport-related walking and cycling: Findings from the USA, Australia and Belgium. The international journal of behavioral nutrition and physical activity 9:70.

Van Holle, V., Deforche, B., Van Cauwenberg, J., Goubert, L., Maes, L., Van de Weghe, N., De Bourdeaudhuij, I., 2012. Relationship between the physical environment and different domains of physical activity in European adults: a systematic review. BMC public health 12:807.

Woodcock, J., Edwards, P., Tonne, C., Armstrong, B.G., Ashiru, O., Banister, D., Beevers, S., Chalabi, Z., Chowdhury, Z., et al., 2009. Public health benefits of strategies to reduce greenhouse-gas emissions: urban land transport. Lancet 374:1930-43.

World Health Organization, 2010. Global recommendations on physical activity for health. World Health Organization, Geneva.

World Health Organization, 2012. Action Plan for implementation of the European Strategy for the Prevention and Control of Noncommunicable Diseases 2012-2016 Copenhagen. 
Table 1. Factors associated with meeting WHO guidelines for physical activity and with total MET-minutes per week.



The overall proportion of respondents meeting the WHO recommendations across all EU countries was $71.4 \%$ and the average MET-mins per week were 2151. 
Table 2. Proportion of respondents 18-64 years old whose local area offers many opportunities for physical activity

\begin{tabular}{|c|c|c|c|c|c|}
\hline & 2002 & 2005 & 2009 & 2013 & p-value* \\
\hline Austria & 87.0 (84.5 to 89.4$)$ & $85.4(82.8$ to 87.9$)$ & $85.9(83.4$ to 88.3$)$ & 89.6 (87.3 to 91.9$)$ & 0.014 \\
\hline Belgium & $81.9(79.1$ to 84.7$)$ & $86.3(83.7$ to 88.9$)$ & $85.5(82.8$ to 88.1$)$ & 90.1 (88.0 to 92.2$)$ & 0.028 \\
\hline Denmark & $90.7(88.5$ to 92.9$)$ & $91.7(89.6$ to 93.8$)$ & $92.3(90.2$ to 94.5$)$ & $92.4(90.1$ to 94.6$)$ & 0.526 \\
\hline Spain & $75.1(71.9$ to 78.3$)$ & $75.5(72.3$ to 78.7$)$ & $78.2(75.1$ to 81.3$)$ & $77.4(74.3$ to 80.4$)$ & 0.252 \\
\hline Finland & $83.1(80.3$ to 85.9$)$ & $90.0(87.7$ to 92.3$)$ & $88.9(86.4$ to 91.4$)$ & $86.9(83.8$ to 90.0$)$ & 0.060 \\
\hline France & 79.1 (76.3 to 82.0$)$ & $87.5(85.1$ to 89.9$)$ & $88.6(86.1$ to 91.1$)$ & 90.4 (88.3 to 92.6$)$ & 0.093 \\
\hline Greece & $71.1(67.8$ to 74.4$)$ & $70.3(66.9$ to 73.8$)$ & $69.4(65.9$ to 72.8$)$ & $62.2(58.7$ to 65.7$)$ & 0.001 \\
\hline Ireland & $74.9(71.7$ to 78.1$)$ & $72.2(69.0$ to 75.5$)$ & $81.2(78.4$ to 84.0$)$ & $82.3(79.0$ to 85.5$)$ & $<0.001$ \\
\hline Italy & 59.4 (55.7 to 63.0$)$ & $70.7(67.4$ to 73.9$)$ & $79.2(76.3$ to 82.1$)$ & $72.9(69.7$ to 76.0$)$ & 0.363 \\
\hline Luxembourg & 79.5 (75.4 to 83.6$)$ & $81.2(76.3$ to 86.2$)$ & 86.5 (82.4 to 90.6$)$ & 91.7 (88.4 to 95.0$)$ & 0.009 \\
\hline Netherlands & $83.8(80.8$ to 86.9$)$ & $94.0(92.2$ to 95.8$)$ & 95.3 (93.7 to 96.8$)$ & $95.8(94.2$ to 97.4$)$ & 0.131 \\
\hline Portugal & 54.5 (50.8 to 58.2$)$ & $57.8(53.8$ to 61.8$)$ & $61.8(58.2$ to 65.5$)$ & $68.0(64.5$ to 71.5$)$ & $<0.001$ \\
\hline Sweden & $78.3(75.2$ to 81.4$)$ & $83.9(81.3$ to 86.5$)$ & $87.4(84.7$ to 90.1$)$ & 90.7 (87.9 to 93.5$)$ & 0.076 \\
\hline Germany & $77.3(76.5$ to 78.1$)$ & $85.2(83.1$ to 87.3$)$ & 88.0 (85.8 to 90.2$)$ & 90.4 (88.5 to 92.2$)$ & $<0.001$ \\
\hline United Kingdom & $76.9(76.1$ to 77.7$)$ & $76.2(73.4$ to 79.0$)$ & 76.8 (73.6 to 79.9$)$ & 78.1 (74.8 to 81.4$)$ & 0.565 \\
\hline Bulgaria & - & $37.9(34.1$ to 41.6$)$ & $45.6(41.6$ to 49.6$)$ & 39.9 (36.1 to 43.7$)$ & 0.307 \\
\hline Cyprus & - & $65.3(60.1$ to 70.5$)$ & $75.9(71.2$ to 80.5$)$ & 76.1 (71.6 to 80.7$)$ & 0.001 \\
\hline Czech Republic & - & $65.5(62.0$ to 69.0$)$ & $62.1(58.6$ to 65.5$)$ & 74.5 (71.4 to 77.6$)$ & $<0.001$ \\
\hline Estonia & - & $64.5(60.7$ to 68.4$)$ & $75.0(71.8$ to 78.3$)$ & $80.4(77.4$ to 83.5$)$ & $<0.001$ \\
\hline Hungary & - & $57.9(54.0$ to 61.8$)$ & $69.1(65.5$ to 72.8$)$ & $63.9(60.3$ to 67.4$)$ & 0.033 \\
\hline Lithuania & - & $71.5(67.9$ to 75.0$)$ & $77.2(74.1$ to 80.4$)$ & $83.0(80.3$ to 85.7$)$ & $<0.001$ \\
\hline Latvia & - & $61.5(57.7$ to 65.2$)$ & $68.6(65.3$ to 71.8$)$ & 74.8 (71.8 to 77.9$)$ & $<0.001$ \\
\hline Malta & - & $51.3(45.3$ to 57.3$)$ & $57.4(51.8$ to 62.9$)$ & $63.4(57.2$ to 69.5$)$ & 0.010 \\
\hline Poland & - & $61.0(57.4$ to 64.6$)$ & $66.3(62.6$ to 70.1$)$ & 75.7 (72.5 to 78.9$)$ & $<0.001$ \\
\hline Romania & - & $56.9(53.1$ to 60.7$)$ & $52.9(49.0$ to 56.7$)$ & $47.1(43.2$ to 51.1$)$ & $<0.001$ \\
\hline Slovenia & - & $78.6(75.7$ to 81.6$)$ & $83.5(80.7$ to 86.3$)$ & 85.5 (83.0 to 88.1$)$ & 0.001 \\
\hline Slovakia & - & $60.3(56.7$ to 63.9$)$ & 62.5 (58.7 to 66.2$)$ & 58.6 (55.0 to 62.2$)$ & 0.385 \\
\hline Croatia & - & $63.0(59.4$ to 66.6$)$ & - & $71.6(68.5$ to 74.7$)$ & 0.001 \\
\hline EU15 & $75.3(74.2$ to 76.5$)$ & $80.3(79.3$ to 81.4$)$ & 82.7 (81.7 to 83.7$)$ & $82.8(81.8$ to 83.7$)$ & $<0.001$ \\
\hline EU28 & - & $71.4(70.4$ to 72.3$)$ & 78.4 (77.6 to 79.3$)$ & $79.0(78.1$ to 79.9$)$ & $<0.001$ \\
\hline
\end{tabular}

*Test for linear trend (binary logistic regression, $\mathrm{P}<0.05$ ), adjusted for gender, age and area of residence. 
Supplementary Table 1 . Sociodemographic characteristics of the 2013 survey sample $(n=20,697)$.

\begin{tabular}{|c|c|c|}
\hline & $\%$ & $95 \% \mathrm{CI}$ \\
\hline \multicolumn{3}{|l|}{ Gender } \\
\hline Female & 50.2 & $49.1-51.2$ \\
\hline Male & 49.8 & $48.8-50.9$ \\
\hline \multicolumn{3}{|l|}{ Age (years) } \\
\hline$\geq 55$ & 19.1 & $18.3-19.9$ \\
\hline $40-54$ & 34.0 & $33.0-35.0$ \\
\hline $25-39$ & 32.3 & $31.3-33.3$ \\
\hline $18-24$ & 14.7 & $13.8-15.5$ \\
\hline \multicolumn{3}{|l|}{ Area of residence } \\
\hline Rural & 31.9 & $30.9-32.9$ \\
\hline Urban & 68.1 & $67.1-69.1$ \\
\hline \multicolumn{3}{|l|}{ Difficulty paying bills } \\
\hline Almost never/Never & 56.8 & $55.7-57.9$ \\
\hline From time to time & 30.1 & $29.2-31.1$ \\
\hline Most of the time & 13.0 & $12.3-13.8$ \\
\hline \multicolumn{3}{|l|}{ Geographical region } \\
\hline Southern Europe & 27.8 & $26.8-28.7$ \\
\hline Western Europe & 33.4 & $32.4-34.5$ \\
\hline Northern Europe & 18.6 & $17.8-19.5$ \\
\hline Eastern Europe & 20.1 & $19.4-20.8$ \\
\hline \multicolumn{3}{|c|}{$\begin{array}{l}\text { Education (age when full-time } \\
\text { education stopped) }\end{array}$} \\
\hline$\leq 15$ years & 12.8 & $12.0-13.5$ \\
\hline 16-19 years & 50.0 & $48.9-51.1$ \\
\hline$\geq 20$ years & 37.2 & $36.2-38.2$ \\
\hline
\end{tabular}


Supplementary Table 2. Proportion of respondents meeting the WHO guidelines for physical activity, by socio-demographic characteristics.

\begin{tabular}{|c|c|c|}
\hline & $\%$ & $95 \% \mathrm{CI}$ \\
\hline \multicolumn{3}{|l|}{ Gender } \\
\hline Female & 66.8 & $65.4-68.2$ \\
\hline Male & 76.1 & $74.7-77.4$ \\
\hline \multicolumn{3}{|l|}{ Age (years) } \\
\hline$\geq 55$ & 64.4 & $62.2-66.6$ \\
\hline $40-54$ & 69.4 & $67.6-71.1$ \\
\hline $25-39$ & 73.9 & $72.2-75.6$ \\
\hline $18-24$ & 79.9 & $77.3-82.5$ \\
\hline \multicolumn{3}{|l|}{ Area of residence } \\
\hline \begin{tabular}{l|l} 
& Rural \\
\end{tabular} & 73.4 & $71.8-75.1$ \\
\hline Urban & 70.5 & $69.3-71.7$ \\
\hline \multicolumn{3}{|l|}{ Difficulty paying bills } \\
\hline Almost never/Never & 75.0 & $73.7-76.3$ \\
\hline From time to time & 66.8 & $64.9-68.6$ \\
\hline Most of the time & 66.4 & $63.6-69.2$ \\
\hline \multicolumn{3}{|l|}{ Geographical region } \\
\hline Southern Europe & 63.8 & $61.8-65.8$ \\
\hline Western Europe & 77.8 & $76.1-79.5$ \\
\hline Northern Europe & 78.0 & $75.7-80.3$ \\
\hline Eastern Europe & 64.7 & $62.8-66.6$ \\
\hline \multicolumn{3}{|c|}{$\begin{array}{l}\text { Education (age when full-time } \\
\text { education stopped) }\end{array}$} \\
\hline$\leq 15$ years & 62.6 & $59.6-65.6$ \\
\hline 16-19 years & 69.8 & $68.4-71.3$ \\
\hline$\geq 20$ years & 77.2 & $75.7-78.6$ \\
\hline
\end{tabular}

